\title{
An intermetallic forming steel under radiation for nuclear applications
}

C. Hofer ${ }^{a, b}$, E. Stergar ${ }^{d}$, S.A. Maloy ${ }^{c}$, Y. Wang ${ }^{c}$, P. Hosemann ${ }^{b^{*}}$

${ }^{a}$ Montanuniveristaet Leoben, Department of Physical Metallurgy and Materials

Testing, Franz Josef Straße 18, 8700 Leoben, Austria

${ }^{b}$ University of California Berkeley, Nuclear Engineering, Berkeley, 94720, CA, USA

${ }^{c}$ Los Alamos National Laboratory, MST-8, Los Alamos 87545, NM, USA

${ }^{d}$ Belgian Nuclear Research Center, SCK•CEN, 2400 Mol, Belgium

${ }^{*}$ Corresponding author

\section{Abstract:}

In this work we investigate the formation and stability of intermetallics formed in maraging steels under ion beam radiation utilizing nanoindentation, microcompression testing and atom probe tomography. A comprehensive discussion analyzing the findings utilizing rate theory is introduced, comparing the aging process to radiation induced diffusion. New findings of radiation induced segregation of undersize solute atoms (Si) towards the precipitates are considered.

Keywords: $\mathrm{PH}$ 13-8 Mo; ion irradiation; micromechanics; atom probe tomography (APT); irradiation effects 
Structural materials in nuclear applications suffer a wide range of microstructural changes under radiation. Consequences of these microstructural and microchemical evolutions are increased hardening, embrittlement, enhanced rates of subcritical cracking, low-temperature irradiation creep, void swelling, loss of ductility and creep resistance [1-4].

The formation of cascades and the formation of a large number of point defects due to particle interaction with materials cannot be avoided initially. However, recent studies have shown that the collection of point defects into voids or clusters can be delayed or avoided by trapping the initial defects at a large number of defect sinks where the defects then annihilate, preventing their accumulation within the lattice [5-8]. The most effective defect sinks and traps have been proven to be interfaces such as grain boundaries or phase boundaries [5-8]. This information has led to the creation of materials with extremely high interface densities which allow for a more radiation tolerant system by utilizing a high density of nm-sized precipitates or multilayer structures [9-11]. The influence of these precipitates or multilayers on the mechanical properties and radiation resistance of the material is controlled by parameters like size, shape, number density or layer thickness and volume fraction. One well known example of this approach are Nanostructured Ferritic Alloys (NFAs), where extremely large numbers of nanoscale oxide particles (in the range of $10^{23}-10^{24} \mathrm{~m}^{-3}$ in number density) are present. These materials are also known as mechanically alloyed oxide dispersion strengthened (ODS) steels [12]. Another example is the widely studied immiscible fcc/bcc metallic 
multilayers such as $\mathrm{Cu} / \mathrm{Nb}$ multilayers realized by physical vapor deposition (PVD) coating techniques or roll bounding $[13,14]$. This microstructure allows the radiation induced point defects or nuclear reaction products to "heal" or become trapped at interfaces. These materials are usually considered top down structures where the manufacturer creates these materials from powders or sputter targets and consolidates those during processing. This leads to the fact that the resulting microstructure can rarely be changed after materials synthesis. NFAs after processing into tubes or thin plates have been shown to be strongly textured with anisotropic properties formed during processing while the $\mathrm{Cu} / \mathrm{Nb}$ layers are by nature anisotropic. Post processing heat treatment usually does not change the structure any more due to the fact that either the grain boundaries are pinned by oxide particles [15] or the $\mathrm{Cu} / \mathrm{Nb}$ interfaces are thermodynamically stable enough that no change occurs upon melting. In addition these materials are difficult to process further via welding or forming due to the very stable microstructure which agglomerates during melting. Only advanced techniques like friction stir welding can be utilized $[16,17]$.

It has been shown in the past that heat treatments on specialized tool steels (maraging steels [18-27]) also lead to the formation of finely dispersed intermetallic precipitates. In the steels discussed here, the microstructure is created by a simple two step heat treatment process which consists of solution annealing and quenching followed by aging. This treatment leads to a highly dislocated martensitic matrix and the aforementioned finely and densely distributed 
intermetallic precipitates increasing the total number of potential defect sinks in the material. As these precipitates are produced only by a heat treatment, the advantage would be that no mechanical alloying step is necessary to introduce a high amount of nm-sized precipitates. While this material creates a large amount of interfaces and potential defect sinks, it is absolutely unclear if and how these sinks are stable under radiation or reactor operation condition. In this paper we explore the formation of the intermetallic precipitates and the change of already formed precipitates under radiation. While in the past maraging steels often times contained Cobalt, an element not desirable to have in a nuclear environment due to activation concerns, Co-free maraging steels have become available. While some $\mathrm{Ni}$ is still present and needed in the alloy to form Ni martensite, the dose rate and activity after reactor irradiation is comparable to conventional stainless steels which also contain a large amount of $\mathrm{Ni}$.

Reactor irradiations are difficult to conduct and can take years to accomplish. Ion beam irradiation has been accepted as a surrogate technique in order to allow cost and time effective early investigation studies to prove the concept of materials behavior under radiation [28]. It also allows one to separate out individual effects based on careful selection of ion species, temperature and energy.

Since ion beam irradiations at low to medium energy usually have a limited penetration depth, small scale mechanical testing and localized microstructural investigation using focused ion beam (FIB) sample preparation are necessary to probe microstructures in these microscale volumes [28]. In addition the size of the 
features of interest is of the nm-scale which makes it necessary to utilize high resolution methods like atom probe tomography (APT), nanoindentation and micro compression testing to examine these materials. Recent investigations have shown that combining these methods gives a powerful method to investigate reactor or ion beam irradiated materials [8]. In this study the above mentioned techniques are utilized in order to evaluate if intermetallic precipitates can form under radiation in maraging steels. This would allow one to use melt-processed homogeneous steels in service which then provide defect sink interfaces upon operation of the nuclear facility. Realizing this concept would reduce costs during manufacturing and provide long term radiation tolerance from the high precipitate density.

\section{Experimental}

For this study the commercially available material Corrax from Uddeholm also often named $\mathrm{PH}$ 13-8 Mo [18], was utilized with its nominal composition given in Table 1. The material was received in the solution annealed state, which is produced by heat treating at $850^{\circ} \mathrm{C}$ for $0.5 \mathrm{~h}$ and subsequent air cooling resulting in a hardness of $34 \mathrm{HRC}$ and a yield strength of $700 \mathrm{MPa}$. Parts of the material were aged at $500^{\circ} \mathrm{C}$ for $2 \mathrm{~h}$. Prior to irradiation the specimens (solution annealed and aged) were mechanically ground and polished with a $1 \mu \mathrm{m}$ diamond suspension as the last step. 
The radiation experiments were performed at the Ion Beam Materials Laboratory (IBML) at the Los Alamos National Laboratory (LANL) using a $3.2 \mathrm{MV}$ tandem accelerator. An area of $2.5 \mathrm{~mm} \times 2 \mathrm{~mm}$ on a $1 \mathrm{~cm} \times 1 \mathrm{~cm}$ sample was irradiated using a $1.3 \mathrm{MeV} 2.5 \mu \mathrm{A}$ proton beam. The samples were kept below $<80^{\circ} \mathrm{C}$ on an air cooled copper stage as described previously in [31] to isolate radiation effects from beam heating effects. A thermocouple was mounted on the sample in order to ensure that the sample is kept at low temperatures. The dose was calculated using the software package SRIM 2008 [30] using the default values for the KinchinPease calculations (fast calculations). The black curve in Fig. 1 represents the induced dose and the red curve illustrates the stopping range of the $\mathrm{H}$ ions implanted. The damage is nearly uniform through the first $8 \mu \mathrm{m}$ of the total range of $10 \mu \mathrm{m}$, resulting in a damage of $2 \mathrm{dpa}$.

After irradiation, the samples were embedded upright in epoxy cold mount to investigate the cross section of the ion beam irradiated specimen. The cross sections were mechanically ground and polished and as the last step of the preparation the samples were polished with $0.1 \mu \mathrm{m}$ colloidal silica on a Buehler vibromet polisher.

Nanoindentation measurements were carried out on Micro Materials NanoTest ${ }^{\mathrm{TM}}$ nanoindenter in order to map out the hardness increase due to irradiation with the method described previously [29, 31-33]. Starting from the edge, 5 rows with 20 indentations to a nominal depth of $200 \mathrm{~nm}$ with a loading time of $20 \mathrm{~s}, 10 \mathrm{~s}$ dwell time and $20 \mathrm{~s}$ unloading time were conducted. The rows were set in an angle of 
about $20^{\circ}$ for better spatial resolution. The indentations were $4 \mu \mathrm{m}$ apart from each other, resulting in a grid of 100 indentations measuring as far as $25 \mu \mathrm{m}$ away from the edge, as shown in Fig. 2. From the nanoindentation curves the hardness values were obtained using the Oliver and Pharr method [34].

Micro compression testing was performed on the solution annealed sample in the irradiated and unirradiated zone. The micro compression test specimens were produced using a FEI Quanta4000 field emission gun dual-beam FIB microscope using $\mathrm{Ga}^{+}$ions with a kinetic energy of $30 \mathrm{keV}$. Rough cuts were performed at a current of $15 \mathrm{nA}$ at an angle of $52^{\circ}$ stage tilt ( $0^{\circ}$ tilt to the ion beam). Subsequently, the pillars were shaped at an angle of $54^{\circ}\left(2^{\circ}\right.$ over tilt) to mill away the visible taper of the sidewalls using lower beam currents and energies to minimize re-deposition and ion beam damage [35]. The micro compression tests were performed with the above mentioned nanoindenter using a $30 \mu \mathrm{m}$ flat punch tip. The pillars were aligned perpendicular to the flat punch prior to the experiments [36] which were carried out in the load-controlled mode with a loading and unloading rate of $1 \mathrm{mN} / \mathrm{s}$.

In addition to mechanical testing APT investigations were conducted at the Center for Advanced Energy Studies (CAES) in Idaho Falls, ID, USA using a LEAP 4000X HR. APT specimens of material in the irradiated and unirradiated zone were prepared with the same FIB as described above using the lift-out method described in $[37,38]$. The experiments were performed in voltage pulsed mode with a specimen temperature of $\sim 60 \mathrm{~K}$, a pulse repetition rate of $200 \mathrm{kHz}$ and a pulse 
fraction of 0.2. The Visualization and Analysis Software IVAS version 3.6 was used for all analysis.

\section{Results}

\subsection{Nanoindentation}

Hardness values obtained on the cross section of the solution annealed sample after irradiation to $2 \mathrm{dpa}$ at room temperature are shown in Fig. 3Error! Reference source not found.a. The blue curve illustrates the calculated damage profile and the red points represent the hardness values from nanoindentation. The low hardness values for the indentations close to the edge result from the extent of the plastic zone into the softer epoxy cold mount. In the irradiated area the hardness is about $6.7 \mathrm{GPa}$, compared to a hardness of about $5.6 \mathrm{GPa}$ in the unirradiated material, showing a significant hardness increase due to irradiation. The irradiated/ unirradiated interface can be accurately measured using nanoindentation and agrees well with SRIM calculations. Also the stopping peak, where the material suffered a much higher damage and, therefore, the hardness increase is higher as well, is clearly detectable.

Figure $3 \mathrm{~b}$ depicts the hardness profile measured on the sample aged for $2 \mathrm{~h}$ at $500^{\circ} \mathrm{C}$ after irradiation to $2 \mathrm{dpa}$ at room temperature irradiation. The hardness of 
the aged material is much higher compared to the solution annealed state. This is due to precipitation hardening during aging compared to the solution annealed state. Irradiation only causes a very small increase in hardness of about $0.4 \mathrm{GPa}$ from 6.7 GPa in the unirradiated area to $7.1 \mathrm{GPa}$ in the irradiated area.

\subsection{Micro compression tests}

On the solution annealed sample micro compression tests were performed in the irradiated and in the unirradiated area. The dimensions of the pillars were obtained by scanning electron microscopy (SEM) prior to testing and are summarized in Table 2. The side lengths of the pillars vary from $4 \mu \mathrm{m}$ to $11.4 \mu \mathrm{m}$. The distance from the edge was measured from the interface specimen/ epoxy cold mount to the center of the pillars. Pillar 3 was a failed test with a destroyed and bent pillar and is not displayed here.

The engineering stress-strain curves measured of all pillars are depicted in Fig. 4. Full lines correlate to the results of the pillars in the unirradiated area, whereas the dotted lines represent the results of the pillars in the irradiated area. The $0.2 \%$ offset of the elastic component was used to measure the yield stress for each pillar.

Unirradiated pillars show an average yield strength under compression of about $1100 \mathrm{MPa}$ followed by work hardening until the experiment was stopped. Pillar 1 and 2 in the irradiated area look very similar, whereas pillar 4 shows much higher 
strength. This can be explained by the position of pillar 4 , which is at the end of range of the ions and suffered a higher dose. However, following strictly the $0.2 \%$ offset rule from the elastic portion of the curve to determine the yield stress leads to a surprisingly low value for pillar 4 due to a small deviation of the linear-elastic line which occurred around $1600 \mathrm{MPa}$ and as a consequence the $R_{c 0.2}$ value of pillar 4 underestimates the increase in strength. This change of slope in the elastic portion of pillar 4 can be seen in Fig. 4 and its origin is not known. However, linear elastic loading continues up to $2200 \mathrm{MPa}$ and, therefore, the real yield strength is probably higher than what is computed by strictly applying the $0.2 \%$ rule. Table 2 summarizes the results from the micro compression tests using $0.2 \%$ offset from the linear elastic region.

\subsection{Atom probe tomography}

Atom maps of $\mathrm{Fe}, \mathrm{Cr}, \mathrm{Ni}, \mathrm{Al}$, and $\mathrm{Si}$ of the solution annealed state are depicted in Fig. 5. The optical impression of a random distribution of all elements was confirmed by a frequency distribution (FD) analysis. If all atoms of one type of element are of random distribution the frequency distribution follows a binomial model [39]. A significant deviation of the binomial model indicates a non-random arrangement of the element.

Atom maps in the irradiated area also appear to be homogenous from visual inspection, as shown in Fig. 6. However, FD analysis revealed that not all elements 
are randomly distributed. The deviation of the observed distribution from the binomial can be quantified by means of a $X^{2}$ statistic test. The hypothesis of a random distribution could be rejected with a confidence threshold of $95 \%$. Since $\mathrm{Ni}$ showed the strongest signs of decomposition a radial distribution function, which calculates the concentration as a function of radial distance of all, in this case $\mathrm{Ni}$, atoms was computed and is illustrated in Fig. 7. For better visualization the concentration was normalized to the bulk concentration. Decomposition mainly enriched in $\mathrm{Ni}$ and $\mathrm{Si}$ can be detected.

As expected, atom maps of the material after aging at $500^{\circ} \mathrm{C}$ for $2 \mathrm{~h}$ reveal precipitates containing $\mathrm{Ni}$ and $\mathrm{Al}$, as shown in Fig. 8. Size and number density of the precipitates were estimated with cluster search algorithm based on the maximum separation method [40], using $0.34 \mathrm{~nm}$ as separation and surrounds distance, $0.17 \mathrm{~nm}$ as erosion distance and a minimum number of 27 ions. The average radius is $0.73 \mathrm{~nm}$ and the number density amounts to $7.5^{\star} 10^{24} \mathrm{~m}^{-3}$. Table 3 contains the chemical composition of the precipitates and the matrix based on the cluster search algorithm. The errors on the concentration values are estimated by

$$
\sigma=\sqrt{\frac{c *(1-c)}{N}}
$$

where $\mathrm{c}$ is the measured concentration and $\mathrm{N}$ the total number of detected atoms $[41,42]$. It can be seen that the particles are enriched in $\mathrm{Ni}, \mathrm{Al}$ and $\mathrm{Mn}$ and on the other hand they are depleted of Fe and Cr. Correspondingly, the matrix is 
depleted of $\mathrm{Al}$ and $\mathrm{Ni}$. Nevertheless, the particles contain a high amount of $\mathrm{Fe}$ and are still far away from stoichiometric NiAl.

In the irradiated area of the aged sample, the precipitates are also discernable as shown in the atom maps in Fig. 9, but in addition to $\mathrm{Ni}$ and $\mathrm{Al}$, Si shows signs of clustering. When carrying out the cluster search on the aged and irradiated sample with a separation and surrounds distance of $0.34 \mathrm{~nm}$, an erosion distance of $0.17 \mathrm{~nm}$ and a minimum number of 34 ions, precipitates with an average radius of $0.72 \mathrm{~nm}$ and a number density of $7.6^{*} 10^{24} \mathrm{~m}^{-3}$ were found. Therefore, size and number density of the precipitates developed during a heat treatment at $500^{\circ} \mathrm{C}$ for $2 \mathrm{~h}$ do not seem to be influenced by proton irradiation at room temperature. The chemical composition of the precipitates obtained by cluster search is also given in Table 3. Comparison of the composition before and after irradiation confirms the assumption that not only $\mathrm{Ni}$ and $\mathrm{Al}$, but also $\mathrm{Si}$ is enriched in the precipitates.

\section{Discussion and theoretical aspects}

The influence of proton irradiation on the mechanical properties and the precipitation kinetics of $\mathrm{PH}$ 13-8Mo was investigated by means of nanoindentation, micro compression testing and APT. Comparison of the solution annealed condition and a condition aged for $2 \mathrm{~h}$ at $500^{\circ} \mathrm{C}$ before and after irradiation showed distinct differences in the material behavior and will be discussed separately. 


\subsection{Solution annealed condition}

Performing nanoindentation on the cross section of a proton irradiated sample allows one to measure the hardness changes as a result of irradiation. The hardness across depth profile of the sample in the solution annealed condition, as shown in Fig. 3a, exhibits a distinct increase of $1.1 \mathrm{GPa}$ in the irradiated material. The irradiated/ unirradiated interface can be clearly seen and the stopping peak of the $\mathrm{H}^{+}$ions is apparent as well.

The property change was also confirmed by micro compression tests. Based on the engineering stress-strain curves depicted in Fig. 4 , the $0.2 \%$ offset yield stress was determined. An average value of $1136 \mathrm{MPa}$ was found for the yield stress under compression of the unirradiated material, compared to an average yield stress of $1695 \mathrm{MPa}$ of the irradiated material. Interestingly, we were also able to sample the stopping peak area. Applying the standard $0.2 \%$ offset for yield strength measurements, no significant difference can be seen between the pillar tested at the stopping peak and the pillar tested in the just as irradiated area. This is due to the fact that small deviations of the linear elastic line lead to lower numbers as it is indicated above and a yield stress of $2200 \mathrm{MPa}$ would be more appropriate. However, following the strict $0.2 \%$ offset rule $1695 \mathrm{MPa}$ is reported in Table 2.

Based on the mechanical properties measured, the question arises if the rather low dose (2 dpa) and low temperature (RT) irradiation actually formed precipitates in 
the metastable material and if so, what kind of precipitates they are. Therefore, APT was conducted to evaluate the actual precipitation structure of the material before and after irradiation. It can be seen in Fig. 6 that all elements are homogenously distributed in the unirradiated condition. Visual inspection of the atom maps of $\mathrm{Fe}, \mathrm{Cr}, \mathrm{Ni}, \mathrm{Al}$, and $\mathrm{Si}$ of the irradiated sample, provided in Fig. 7, does not show obvious clustering. However, FD analysis shows a significant deviation from the binomial distribution, indicating that decomposition took place. The radial distribution function of $\mathrm{Ni}$, shown in Fig. 8, revealed zones enriched in $\mathrm{Ni}$ and $\mathrm{Si}$ and depleted of $\mathrm{Fe}$ and $\mathrm{Cr}$. While the observed local enrichment is significantly less pronounced than in a fully heat treated material, it does show early stages of a precipitation process. Due to the fact that the precipitate precursors are very small and only seen based on statistical analysis further TEM was not conducted since the decomposed zones would not be visible. Since the material did not see increased temperature during the irradiation the only explanation for the formation of precipitate pre-cursors (decomposition) would be based on radiation-enhanced diffusion. During irradiation a large number of vacancies and interstitials are generated. Since diffusion is based on the mobility of point defects, the excess amount of vacancies and interstitials cause enhanced diffusion. Consequently, they lead to defect aggregation or precipitation, depending on the balance between defect production rate and the loss of point defects due to recombination or sinks [43]. 
In this work an attempt was made to calculate a diffusion coefficient during irradiation to evaluate if radiation-enhanced diffusion is a possible explanation for the observed decomposition and precipitate pre-curser formation. The steady state vacancy concentration in the material can be calculated using the approach outlined in $[43,44]$ and was applied to a similar problem as demonstrated in [45].

$$
\begin{gathered}
c_{\mathrm{v}}^{\mathrm{SS}}=-\frac{\mathrm{K}_{\mathrm{is}} \mathrm{C}_{\mathrm{s}}}{2 * \mathrm{~K}_{\mathrm{iv}}}+\left[\frac{\mathrm{K}_{0} \mathrm{~K}_{\mathrm{is}}}{\mathrm{K}_{\mathrm{iv}} \mathrm{K}_{\mathrm{vs}}}+\frac{\mathrm{K}_{\mathrm{iS}}^{2} \mathrm{C}_{\mathrm{s}}^{2}}{4 * \mathrm{~K}_{\mathrm{iv}}^{2}}\right]^{\frac{1}{2}} \\
c_{\mathrm{i}}^{\mathrm{SS}}=-\frac{\mathrm{K}_{\mathrm{vs}} \mathrm{C}_{\mathrm{S}}}{2 * \mathrm{~K}_{\mathrm{iv}}}+\left[\frac{\mathrm{K}_{0} \mathrm{~K}_{\mathrm{vS}}}{\mathrm{K}_{\mathrm{iv}} \mathrm{K}_{\mathrm{is}}}+\frac{\mathrm{K}_{\mathrm{vS}}^{2} \mathrm{C}_{5}^{2}}{4 * \mathrm{~K}_{\mathrm{iv}}^{2}}\right]^{\frac{1}{2}}
\end{gathered}
$$

In this equations $\mathrm{C}_{\mathrm{s}}$ represents the defect sink concentration, $\mathrm{K}_{0}$ the defect production rate, $\mathrm{K}_{\mathrm{iv}}$ the vacancy-interstitial recombination rate coefficient, $\mathrm{K}_{\mathrm{vs}}$ the vacancy-sink reaction rate coefficient and $\mathrm{K}_{\text {is }}$ the interstitial-sink reaction rate coefficient. The vacancy production rate $\mathrm{K}_{0}$ is obtained from the SRIM calculation and amounts to $2.5^{\star} 10^{18} \mathrm{vac} /\left(\mathrm{cm}^{3 *} \mathrm{~s}\right)$. The most important sinks in solution annealed $\mathrm{PH}$ 13-8 Mo are dislocations and therefore, the dislocation density $\rho_{\mathrm{D}}=10^{12} \mathrm{~m}^{-2}[46]$ is included in the equation for the sink concentration

$$
\mathrm{C}_{\mathrm{s}}=\frac{\rho_{\mathrm{D}}}{\mathrm{a}_{0}}
$$

The interstitials and vacancies migrate by random walk diffusion, annihilating each other by mutual recombination or at unsaturable fixed sinks. Sinks and defects are assumed to be distributed homogeneously and no preferential absorption of specific point defects at specific sinks occurs. Thus, the rate constants are as follows 


$$
\begin{aligned}
& \mathrm{K}_{\mathrm{iv}} \approx 4 * \pi * \mathrm{r}_{\mathrm{iv}} * \mathrm{D}_{\mathrm{i}} \\
& \mathrm{K}_{\mathrm{is}}=4 * \pi * \mathrm{r}_{\mathrm{is}} * \mathrm{D}_{\mathrm{i}} \\
& \mathrm{K}_{\mathrm{vs}}=4 * \pi * \mathrm{r}_{\mathrm{vs}} * \mathrm{D}_{\mathrm{v}}
\end{aligned}
$$

where $r_{i v}, r_{v s}$ and $r_{i s}$ are interaction radii for the reactions between the species. $r_{v s}$ and $r_{\text {is }}$ were taken to be equal to the lattice parameter $a_{0}$, and $r_{i v}$ is about twice as much [43]. The diffusion coefficient for vacancies $D_{v}$ depends on the number of nearest neighbors $\mathrm{z}$, the diffusion mechanism and the crystal structure, both considered in the parameter $A$, the lattice constant $a_{0}$, and the jump frequency $\omega$

$$
\mathrm{D}_{\mathrm{v}}=\alpha * \mathrm{a}_{0}^{2} * \omega
$$

with

$$
\alpha=\frac{1}{6} * \mathrm{Z} * \mathrm{~A}^{2}
$$

The jump frequency is generally assumed as the Debye frequency $v_{D} \approx 10^{13} \mathrm{~s}^{-1}$ multiplied with the Boltzmann factor, which takes into account the probability of success

$$
\omega=v * \exp ^{\left(\frac{\mathrm{S}_{\mathrm{m}}^{\mathrm{V}}}{\mathrm{kT}}\right)} * \exp ^{\left(\frac{-\mathrm{E}_{\mathrm{m}}^{\mathrm{V}}}{\mathrm{kT}}\right)}
$$

The vacancy migration entropy $S_{m}^{v}$ can be neglected and therefore, the diffusion coefficient results in

$$
D_{v}=\alpha * a_{0}^{2} * v * \exp \left(\frac{-E_{m}^{v}}{k T}\right)
$$


with a vacancy migration energy $\mathrm{E}_{\mathrm{m}}^{\mathrm{v}}$ of $0.68 \mathrm{eV}$ [64]. The diffusion coefficient for interstitials $D_{i}$ is calculated the same way as for vacancies with an interstitial migration energy of $0.33 \mathrm{eV}$ [65]. The diffusion coefficient of lattice atoms is given by

$$
\mathrm{D}_{\text {rad }}=\mathrm{D}_{\mathrm{v}} \mathrm{C}_{\mathrm{v}}+\mathrm{D}_{\mathrm{i}} \mathrm{C}_{\mathrm{i}}
$$

The diffusion coefficient under irradiation added up to $3.21^{*} 10^{-18} \mathrm{~cm}^{2} / \mathrm{s}$. The input values for the interstitial and vacancy migration energy are self-interstitials for $\mathrm{Fe}$ in alpha Fe. While we do recognize the fact that those are likely different from the elements segregating we would not expect a significant difference are therefore appropriate approximations for the diffusion coefficient estimation presented here. To set this value into proportion, a diffusion coefficient during an aging heat treatment, where typically the intermetallic precipitates are formed $\left(500^{\circ} \mathrm{C}\right)$, was calculated based on thermal activation using the vacancy formation energy $\mathrm{G}_{\mathrm{f}}^{\mathrm{v}}$, the Boltzmann constant $\mathrm{k}$, and the aging temperature $\mathrm{T}$

$$
C_{\mathrm{v}}=\exp ^{\left(\frac{-G_{f}^{\mathrm{v}}}{\mathrm{kT}}\right)}
$$

The vacancy formation energy was taken to be $1.4 \mathrm{eV}$ as the energy for vacancy formation in $\alpha-F e$ [47]. The diffusion coefficient of lattice atoms by way of the vacancy mechanism is given by

$$
\mathrm{D}_{500^{\circ} \mathrm{C}}=\mathrm{D}_{\mathrm{v}} \mathrm{C}_{\mathrm{v}}
$$


For a body-centered material aged at $500^{\circ} \mathrm{C}$ for $2 \mathrm{~h}$ the diffusion coefficient accounts for $2.27^{*} 10^{-16} \mathrm{~cm}^{2} / \mathrm{s}$.

Based on the above calculations, it was found, that the vacancys' diffusion coefficient during irradiation is two orders of magnitude smaller than during a heat treatment at $500^{\circ} \mathrm{C}\left(3.21^{*} 10^{-18} \mathrm{~cm}^{2} / \mathrm{s}\right.$ compared to $\left.2.27^{*} 10^{-16} \mathrm{~cm}^{2} / \mathrm{s}\right)$. Considering Einstein's diffusion law and the different exposure times $(20 \mathrm{~h}$ for the irradiation vs. $2 \mathrm{~h}$ for the heat treatment) a difference in diffusion length of one order of magnitude persists. The calculation above is a rather crude approach but similar to what was done in [45] and it can be assumed here, that the diffusion induced by radiation is just high enough to allow decomposition but still too low for a full precipitation process to occur during the irradiation time.

Guo et al. [48] also observed hardening effects during the initial stage of aging before detectable precipitates formed. They attributed this increase in hardness to the redistribution of atoms. Reich et al. [49] suggested a solute-dislocation interaction, where solute atoms segregate to existing dislocations causing dislocation locking. However, no evidence of this was found (line enrichment of specific atom species) using APT. Besides the decomposition also radiationinduced defects affect the hardness of course (e.g. dislocation loops). Dislocation loops act as dispersed barriers for dislocation glide and, therefore, increase the yield strength. TEM examination would be necessary to visualize them, but this is beyond the scope of this work. However, the dramatic increase in hardness and yield stress on an already martensitic and relatively high dislocation density 
containing material might not be explainable by dislocation loops alone. Experiments conducted for longer irradiation times as well as irradiation at higher temperatures, which allow matching the diffusion length to heat treatments, might lead to better developed and similar precipitation structure than that found during heat treatments. These experiments could support this hypothesis and will be conducted in the future. Interestingly, it appears that the irradiation conditions used in this work do not change the precipitation distribution or size but only the chemistry, as discussed below.

\subsection{Irradiation of the aged condition}

As can be seen in Fig. 3b, nanoindentation only revealed a very small increase in hardness due to irradiation in the sample aged at $500^{\circ} \mathrm{C}$ for $2 \mathrm{~h}$. The precipitates formed during the aging treatment delayed the radiation damage. Van Renterghem et al. [49] suggested that existing precipitates in $\mathrm{PH}$ 13-8 Mo are not influenced by radiation because number density and radius do not change during irradiation. They attributed the hardness increase to the formation of dislocation loops, which we agree with. This adds another data point to the previous section, where we discuss that the dramatic hardness increase from the as received material and irradiated material cannot be explained with the formation of dislocation loop structure alone. 
In this work, it was found that the radius and number density are also comparable before and after irradiation, but it was observed that the composition of the precipitates changed during the irradiation process. The chemical analysis of the precipitates (Table 3) revealed that the Al concentration decreased while the $\mathrm{Si}$ concentration increased in the precipitates due to irradiation. Zhang et al. [45] also detected a change in composition of $\mathrm{Cu}$-rich precipitates after irradiation of a reactor pressure vessel (RPV) steel. The concentration of $\mathrm{Cu}$ was found to significantly increase in the precipitates, indicating that irradiation leads to the equilibrium precipitate composition. According to that, the radiation-enhanced diffusion should lead to an increase in the concentration of $\mathrm{Ni}$ and $\mathrm{Al}$ in the precipitates in irradiated $\mathrm{PH}$ 13-8 Mo approaching the equilibrium composition of NiAl. However, the Al concentration decreases considerably and Si enriches in the precipitates. Likewise, the clusters resulting from proton irradiation of the solution annealed condition also exhibit a clear enrichment of $\mathrm{Si}$, as illustrated in Fig. 7. According to [45] NiAl has a solubility of over 10 at $\%$ for $\mathrm{Si}$ at $550^{\circ} \mathrm{C}$, however, $\mathrm{Si}$ enrichment has not been detected before in NiAl precipitates in $\mathrm{PH} 13-8 \mathrm{Mo}$ [25]. This might indicate that a change of precipitate type takes place. The system Ni-Al$\mathrm{Si}$ has a rather rich ternary phase diagram [51] and several Ni-Si-Al phases are possible to exist.

In the literature it has been reported that $\mathrm{Si}$ and other under-sized solute atoms are coupled to interstitials [52], evident by the formation of $\mathrm{Ni}_{3} \mathrm{Si}$ on interstitial loops during irradiation [53-55]. If it can be seen that $\mathrm{Si}$ is moving with interstitials, it can 
be stated that the intermetallic precipitates found here attracting Si under radiation are sinks for interstitials. However, in $[56,57]$ Fe-Ni-Al alloys were studied via positron annihilation spectroscopy (PAS) and TEM, it was found that the nanoscale $Y$ ' interfaces efficiently remove vacancies as well in the $Y-\mathrm{Ni}_{3} \mathrm{Al}$ system. In [56] the lattice strain is discussed as an efficient force attracting the defects to the interface and removing them. However, there the $y$ ' interface is considered with a lattice mismatch $\delta$ of $0.7 \%$. In our study the lattice mismatch is about $25 \%$ and, therefore, significant larger than for $\mathrm{Y}^{\prime}$. Interestingly, it was also found that addition of $\mathrm{Si}$ decreases the lattice parameter of $\mathrm{Ni}_{3} \mathrm{Al}$ from $3.57 \AA$ to $3.51 \AA$ in the $\mathrm{Ni}_{3} \mathrm{Si}$ phase [58], while the lattice constant of bcc Fe with an addition of $9 \% \mathrm{Ni}$ is $2.868 \AA$ according to [59]. Of course the question of coherency arises with such a large lattice constant mismatch, but it was found that these small precipitates are coherent [60].

It is clearly evident that the precipitates delay the materials degradation due to irradiation as it was also found in $[56,57]$. It seems that precipitates act as recombination centers for both vacancy and interstitial defects. In [61] the reduction of defect accumulation was attributed to the interaction of precipitates with dislocations. Another model [62] proposes that the elastic stresses arising around coherent precipitates force the recombination of point defects. This is questioned due to the low interaction between point defects and stress fields in general. Arokiam et al. [63] suggested that clusters of self-interstitial atoms created in 
displacement cascades become trapped inside precipitates and act as strong nonsaturated sinks for vacancies.

\section{Conclusions}

In summary it was found that a Co-free maraging steel forms early stages of decomposition under room temperature ion beam irradiation to 2 dpa using protons. Comparing vacancy diffusion coefficients it was found that the radiation induced diffusion is 2 orders of magnitude less than the diffusion encountered at the typical aging temperature of $500^{\circ} \mathrm{C}$. This is consistent with the incomplete formation of precipitate pre-cursors.

It was also found that the already formed intermetallic precipitates do not change shape or size under room temperature irradiation but they do change their chemistry. $\mathrm{Si}$ is found in addition to the Ni-Al, leading to a discussion about defect absorption in these precipitates.

Although more research is needed to better understand how coherent intermetallic precipitates influence the evolution of point defects, it appears to be a promising approach to further increase the radiation resistance of martensitic steels.

\section{Acknowledgement}


The Authors want to thank the Marshall Plan Foundation for supporting student exchange between Austria and the United States.

In addition we want to thank the DOE-NEET program for supporting this research under the \#DE-NE0000536000.

Atom Probe tomography was supported by the Center for Advanced Energy Studies (CAES) a user facility at INL.

\section{References}

[1] Zinkle SJ, Busby JT. Mater Today 2009;12:12.

[2] Garner FA, Toloczko MB, Sencer BH. J Nucl Mater 2000;276:123.

[3] Kenik EA, Busby JT. Mater Sci Eng R 2012;73:67.

[4] Jia Z, Was GS. Microsc Microanal 2010;16:1598.

[5] Beyerlein IJ, Caro A, Demkowicz MJ, Mara NA, Misra A, Uberuag BP, Mater Today 2013;16:443.

[6] Yu KY, Liu Y, Sun C, Wang H, Shao L, Fu EG, Zhang X. J Nucl Mater 2012;425:140.

[7] Sun C, Yu KY, Lee JH, Liu Y, Wang H, Shao L, Maloy SA, Hartwig KT, Zhang X. J Nucl Mater 2012;420:235.

[8] Hosemann P, Stergar E, Lei P, Dai Y, Maloy SA, Pouchon MA, Shiba K, Hamaguchi D, Leitner H. J Nucl Mater 2011;417:274.

[9] Odette GR, Hoelzer DT. JOM 2010;62:84. 
[10] Hsiung LL, Fluss MJ, Tumey SJ, Choi BW, Serruys Y, Willaime F, Kimura A, Phys Rev B 82,1841032010.

[11] Hosemann P, Stergar E, Nelson AT, Vieh C, Maloy SA. Mater Res Soc Symp Proc 2011;1298:217.

[12] Odette GR, Allinger MJ, Wirth BD, Ann Rev Mater Res 2008;38:471.

[13] Demkowicz MJ, Hoagland RG, Hirth JP. Phys Rev Let 2008;100:126102-1$126102-4$

[14] Lee SB, LeDonne JE, Lim SCV, Beyerlein IJ, Rollett AD, Acta Mater 2012;60:1747.

[15] Oksiuta Z, Hosemann P, Vogel SC, Baluc N, J Nucl Mater 2014;451:320.

[16] Baker BW, Menon ESK, Brewer LN. Microsc Microanal 2013;19:714.

[17] West M, Jasthi B, Hosemann P, Sodesetti V. Frict Stir Weld Process 2011;Vl:33.

[18] http://www.bucorp.com/corrax_p.htm. s.l.: Boehler-Uddeholm, August 2014.

[19] Taillard R, Pineau A, Thomas BJ. Mater Sci Eng 1982;54:209.

[20] Taillard R, Pineau A. Mater Sci Eng 1982;56:219.

[21] Guo Z, Sha W, Li D. Mater Sci Eng A 2004;373:10.

[22] Decker RF. Source Book on Maraging Steels, ISBN: 0871700794, 9780871700797 ASM, Metals Park, OH; 1979.

[23] Vasudevan K, Kim SJ, Wayman CM. Metall Trans A 1990;21:2655.

[24] Sha W, Cerezo A, Smith GDW. Metall Trans A 1993;24:1251.

[25] Schober M, Schnitzer R, Leitner H. Ultramicroscopy 2009;109:553.

[26] Leitner H, Schober M, Schnitzer R, Zinner S. Mater Sci Eng A 2011;528:5264. 
[27] Ping DH, Ohnuma M, Hirakawa Y, Kadoya Y, Hono K, Mater Sci Eng A 2005;394:285.

[28] Hosemann P, Swadener JG, Kiener D, Was GS, Maloy SA, Li N. J Nucl Mater 2008;375:135.

[29] Vieh C, Greco RR, Kabra S, Valdez JA, Cappiello MJ, Maloy SA. J Nucl Mater 2009;389:239.

[30] Ziegler JF, Ziegler MD, Biersack JP, Nucl Instrum Meth B 2010;268:1818.

[31] Rice RM, Stoller RE. J Nucl Mater 1997;244:219.

[32] Hosemann P, Kiener D, Wang Y, Maloy SA. J Nucl Mater 2012;425:136.

[33] Kiener D, Minor AM, Anderoglu O, Wang Y, Maloy SA, Hosemann P. JMR 2012;27:2724.

[34] Oliver WC, Pharr GM, JMR 1992;7:1564.

[35] Uchic MD, Dimiduk DM, Florando JN, Nix WD. Science 2004;305:986.

[36] Shin C, Lim S, Jin HH, Hosemann P, Kwon J. J Nucl Mater 2014;444:43-48

[37] Miller MK, Russell KF, Thompson K, Alvis R, Larson DJ. Microsc Microanal 2007; 13:428.

[38] Saxey DW, Cairney JM, McGrouther D, Honma T, Ringer SP. Ultramicroscopy 2007;107:756.

[39] Moody MP, Stephenson LT, Ceguerra AV, Ringer SP. Microsc Res Techniq 2008;71:542.

[40] Cerezo A, Davin L, Surf Interface Anal 2007;39:184.

[41] Danoix F, Grancher G, Bostel A, Blavette D, Ultramicroscopy 2007;107:739. 
[42] Miller MK. Atom Probe Tomography, first ed. New York; Kluwer Academic/ Plenum Publishers; 2000.

[43] Was GS. Fundamentals of Radiation Materials Science, first ed. Heidelberg; Springer Verlag Berlin; 2007.

[44] Sizemann R, J Nucl Mater 1987;69/70:386.

[45] Z.W. Zhang et al., Acta Mater 2012;60:3034.

[46] Pereloma EV, Shekhter A, Miller MK, Ringer SP. Acta Mater 2004;52:5589.

[47] Luebbehusen M, Mehrer H. Acta Metall Mater 1990;38:283.

[48] Guo Z, Sha W, Vaumousse D. Acta Mater 2003;51:101.

[49] Reich L, Ringer SP, Hono K. Philos Mag Lett 1999;9:639.

[50] Van Renterghem W, Al Mazouzi A, Van den Berghe S. J Nucl Mater 2007;360:128.

[51] Raghavan V. J Phase Equilib Diff 2005; 26:262.

[52] Ardell AJ. Chapter "Radiation-induced solute segregation in alloys" in Materials Issues for Generation IV Systems, Cargèse, Corsica, France: Springer; 2008.

Page 285-310; ISBN: 978-1-4020-8422-5

[53] Rehn LE, Okamoto PR. Non-equilibrium segregation in irradiated alloys, in:

Nolfi Jr FN (Ed.). Phase Transformation During Irradiation. London: Applied

Science Publishers; 1983.

[54] Ardell AJ, Janghorban K. Irradiation-Induced Phase Transformations in Binary

$\mathrm{Ni}$ and Pd Base Alloys, in: Nolfi Jr FN (Ed.). Phase Transformation During

Irradiation. London: Applied Science Publishers; 1983.

[55] Barbu A, Ardell AJ. Scripta Metall 1975;9:1233. 
[56] Druzhkov AP, Perminov DA, Pecherkina NL, Philosophical Magazine 2008;88:959.

[57] Druzhkov AP, Perminov DA, Arbuzov VL, J Phys Cond Matter 2006;18:365.

[58] Mishima Y, Ochiai S, Suzuki T. Acta Metall 1985;33:1161.

[59] Zwell L, Carnahan DE, Speich GR. Metall Trans 1970;1:1007.

[60] Erlach SD, Leitner H, Bischof M, Clemens H, Danoix F, Lemarchand D, Siller I.

Mater Sci Eng A 2006;429:96.

[61] Etienne A, Radiguet B, Pareige P. J Nucl Mater 2010;406:251.

[62] Ardell AJ, Nicholson RB, Eshelby JD. Acta Metall 1966;14:1295.

[63] Arokiam AC, Barashev AV, Bacon DJ, Osetsky YN. Philos Mag 2007;87:925.

[64] A. Vehanen, P. Hautojarvi, J. Johansson, J. Yli-Kauppila, P. Moser; Phys Rev 8, (1982)

[65] R. A. Johnson: Phys. Rev.134 (1964) A1329-A1336 


\section{Tables:}

Table 1

Typical chemical composition of Uddeholm Corrax according to the data sheet of 2014 [18].

\begin{tabular}{ccccccccc}
\hline & Fe & C & Cr & Ni & Al & Mo & Mn & Si \\
\hline \hline $\mathrm{m} \%$ & Bal. & 0.03 & 12 & 9.2 & 1.6 & 1.4 & 0.3 & 0.3 \\
at\% & Bal. & 0.14 & 12.6 & 8.6 & 3.2 & 0.8 & 0.3 & 0.6 \\
\hline
\end{tabular}

Table 2

$0.2 \%$ offset yield strength of the micro pillars of the solution annealed condition.

\begin{tabular}{lcc}
\hline & $\begin{array}{c}\text { Distance from } \\
\text { the edge }[\mu \mathrm{m}]\end{array}$ & $\mathrm{R}_{\mathrm{c0.2}}\left[\mathrm{N} / \mathrm{mm}^{2}\right]$ \\
\hline \hline Pillar 1, unirr. & - & 990 \\
Pillar 2, unirr. & - & 1260 \\
Pillar 3, unirr. & - & 1160 \\
Pillar 1, irr. & 5.9 & 1660 \\
Pillar 2, irr. & 7.6 & 1730 \\
Pillar 4, irr. & 8.8 & 1650 \\
\hline
\end{tabular}

Table 3

Chemical composition of the matrix and the precipitates in at $\%$ in the irradiated and unirradiated area of the material aged at $500^{\circ} \mathrm{C}$ for $2 \mathrm{~h}$.

\begin{tabular}{lcccccccc}
\hline & $\mathbf{F e}$ & $\mathbf{C r}$ & $\mathbf{N i}$ & $\mathbf{A l}$ & $\mathbf{M o}$ & $\mathbf{M n}$ & $\mathbf{S i}$ & $\mathbf{C}$ \\
\hline \hline unirradiated & & & & & & & & \\
matrix & Bal. & 13.04 & 6.36 & 1.91 & 0.87 & 0.26 & 0.64 & 0.06 \\
& & $( \pm 0.02)$ & $( \pm 0.02)$ & $( \pm 0.01)$ & $( \pm 0.003)$ & $( \pm 0.003)$ & $( \pm 0.005)$ & $( \pm 0.001)$ \\
precipitates & Bal. & 6.66 & 25.97 & 15.84 & 0.45 & 1.02 & 0.82 & 0.05 \\
& & $( \pm 0.05)$ & $( \pm 0.10)$ & $( \pm 0.08)$ & $( \pm 0.01)$ & $( \pm 0.02)$ & $( \pm 0.02)$ & $( \pm 0.004)$
\end{tabular}




\begin{tabular}{|c|c|c|c|c|c|c|c|c|}
\hline matrix & Bal. & $\begin{array}{c}13.05 \\
( \pm 0.02)\end{array}$ & $\begin{array}{c}6.69 \\
( \pm 0.01)\end{array}$ & $\begin{array}{c}2.71 \\
( \pm 0.01)\end{array}$ & $\begin{array}{c}0.92 \\
( \pm 0.005)\end{array}$ & $\begin{array}{c}0.34 \\
( \pm 0.003)\end{array}$ & $\begin{array}{c}0.51 \\
( \pm 0.004)\end{array}$ & $\begin{array}{c}0.03 \\
( \pm 0.001)\end{array}$ \\
\hline \multirow[t]{2}{*}{ precipitates } & Bal. & 7.29 & 27.26 & 10.73 & 0.34 & 0.56 & 2.06 & 0.02 \\
\hline & & $( \pm 0.02)$ & $( \pm 0.04)$ & $( \pm 0.03)$ & $( \pm 0.004)$ & $( \pm 0.006)$ & $( \pm 0.01)$ & $( \pm 0.001)$ \\
\hline
\end{tabular}

\section{Figures:}

Fig. 1. Dose over depth profile calculated using SRIM 2008.

Fig. 2. (a) Schematic sketch of the nanoindentation measurements. (b) Secondary electron SEM image of one array of indentations on the cross section of the sample aged for $2 \mathrm{~h}$ at $500^{\circ} \mathrm{C}$.

Fig. 3. Hardness measured after irradiation with nanoindentation on the cross section of the (a) solution annealed condition and the calculated damage profile over the distance from the edge and (b) the aged sample.

Fig. 4. Engineering stress-strain curves of pillars in the unirradiated area (full lines) and the irradiated area (dotted lines).

Fig. 5. Atom maps of $\mathrm{Fe}, \mathrm{Cr}, \mathrm{Ni}, \mathrm{Al}$, and $\mathrm{Si}$ the solution annealed state. There are no segregations visible.

Fig. 6. Atom maps of $\mathrm{Fe}, \mathrm{Cr}, \mathrm{Ni}, \mathrm{Al}$, and $\mathrm{Si}$ of the solution annealed material after 2 dpa proton irradiation.

Fig. 7. Radial distribution function of $\mathrm{Ni}$ of the solution annealed condition after proton irradiation. 
Fig. 8. Atom maps of $\mathrm{Fe}, \mathrm{Cr}, \mathrm{Ni}, \mathrm{Al}$, and $\mathrm{Si}$ of the material after aging for $2 \mathrm{~h}$ at $500^{\circ} \mathrm{C}$.

Fig. 9. Atom maps of $\mathrm{Fe}, \mathrm{Cr}, \mathrm{Ni}, \mathrm{Al}$, and $\mathrm{Si}$ after $2 \mathrm{~h}$ of aging at $500^{\circ} \mathrm{C}$ and $2 \mathrm{dpa}$ proton irradiation. 


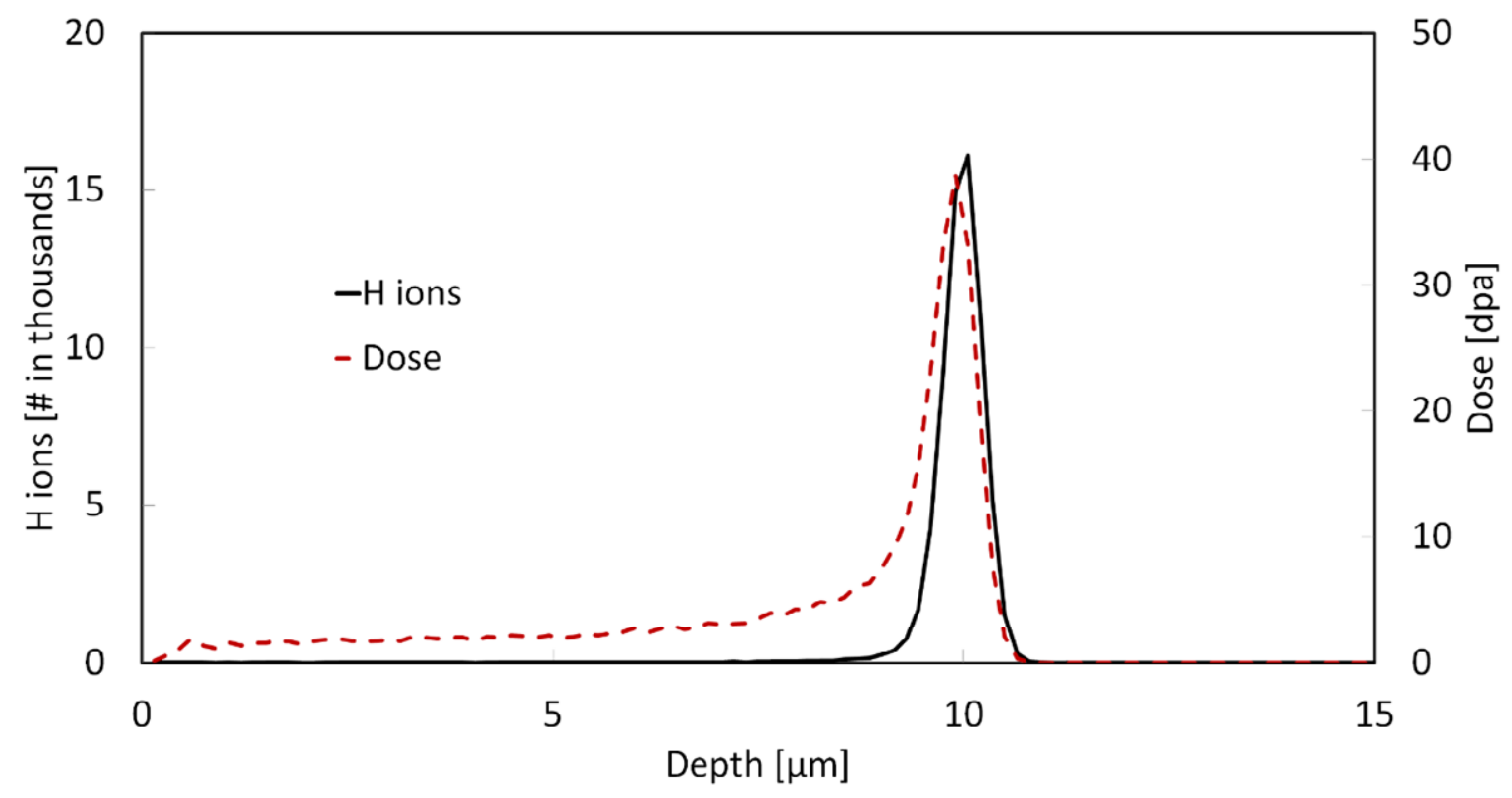

Fig. 1. Dose over depth profile calculated using SRIM 2008.
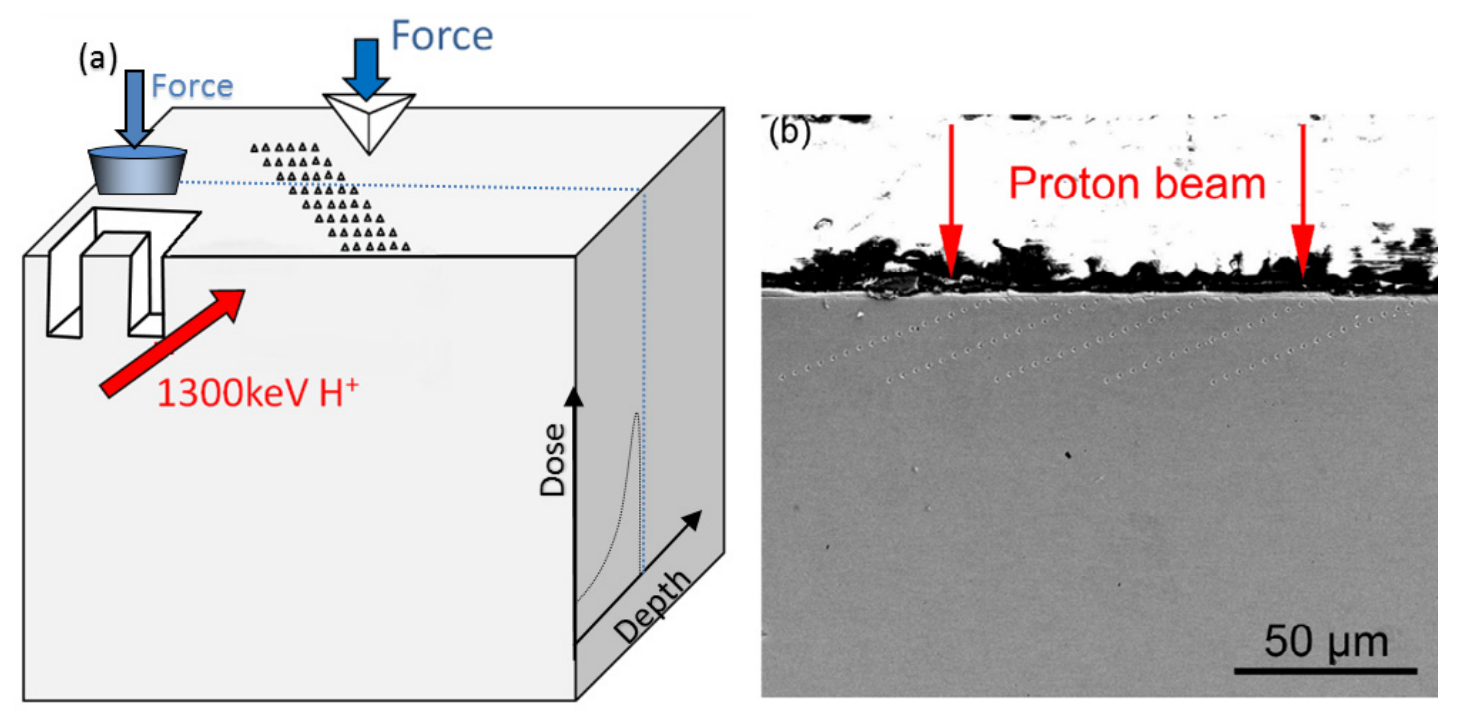

Fig. 2. (a) Schematic sketch of the nanoindentation and micro compression measurements in the ion beam irradiated region. (b) Secondary electron SEM image of one array of indentations on the cross section of the sample aged for $2 \mathrm{~h}$ at $500^{\circ} \mathrm{C}$. 

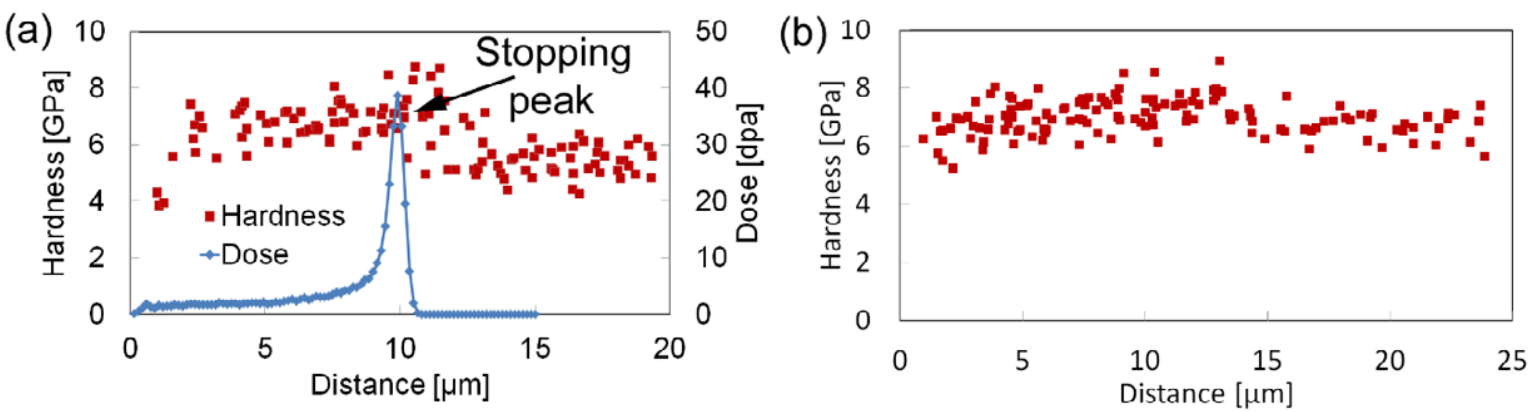

Fig. 3. Hardness measured with nanoindentation on the cross section of the (a) solution annealed condition and the calculated damage profile over the distance from the edge and (b) the aged sample.

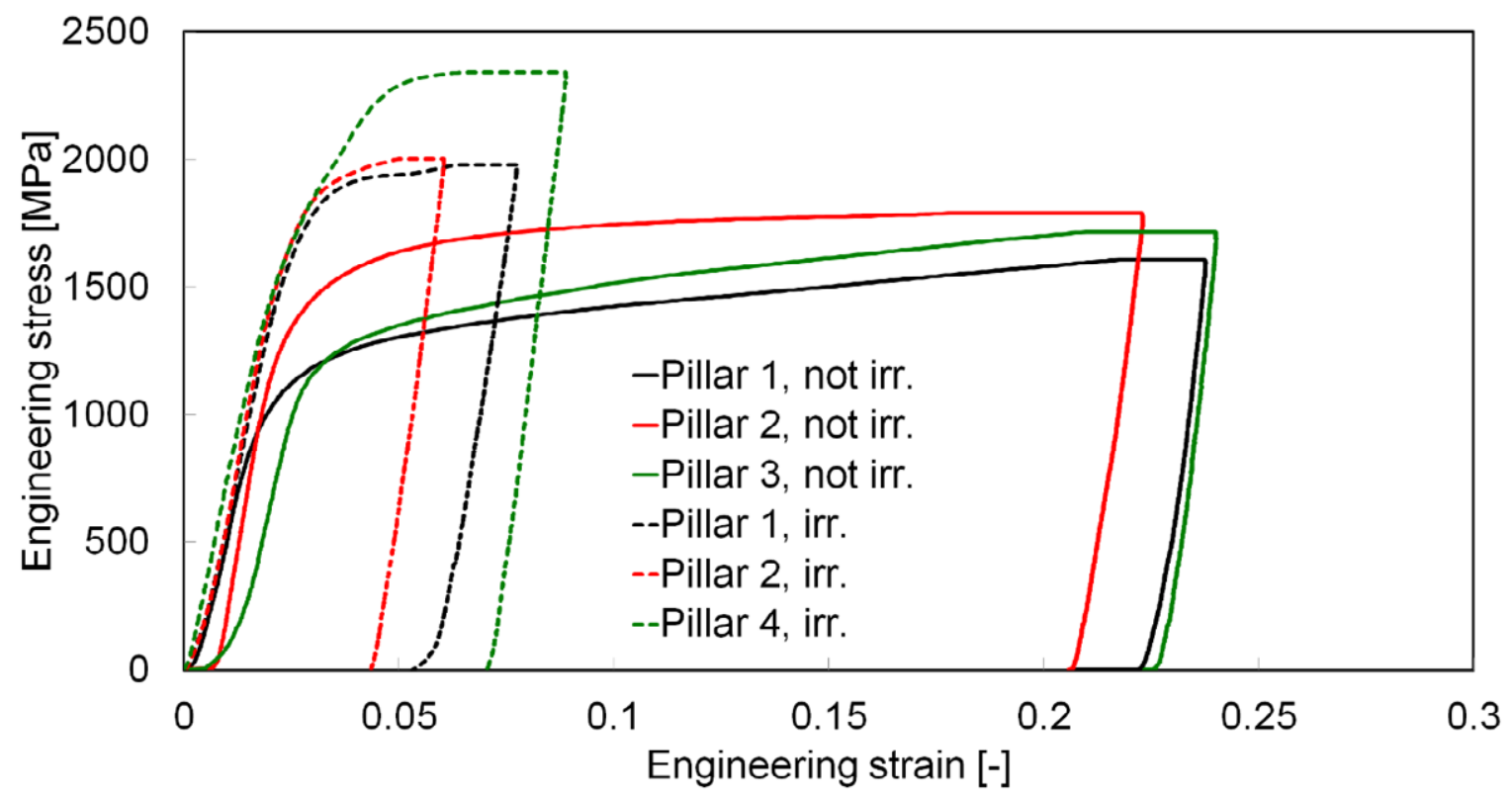

Fig. 4. Engineering stress-strain curves of pillars in the unirradiated area (full lines) and the irradiated area (dotted lines). 

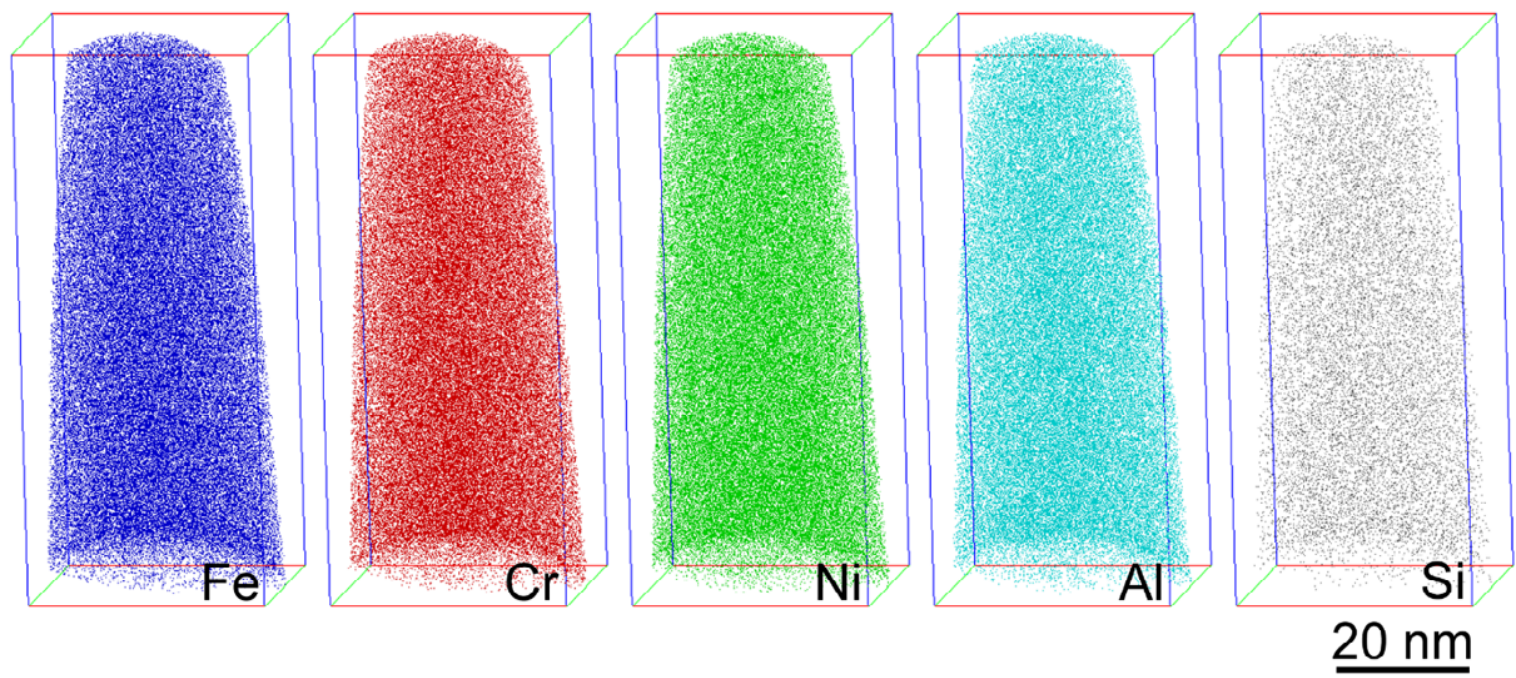

Fig. 5. Atom maps of $\mathrm{Fe}, \mathrm{Cr}, \mathrm{Ni}, \mathrm{Al}$, and $\mathrm{Si}$ the solution annealed state. There are no segregations visible.

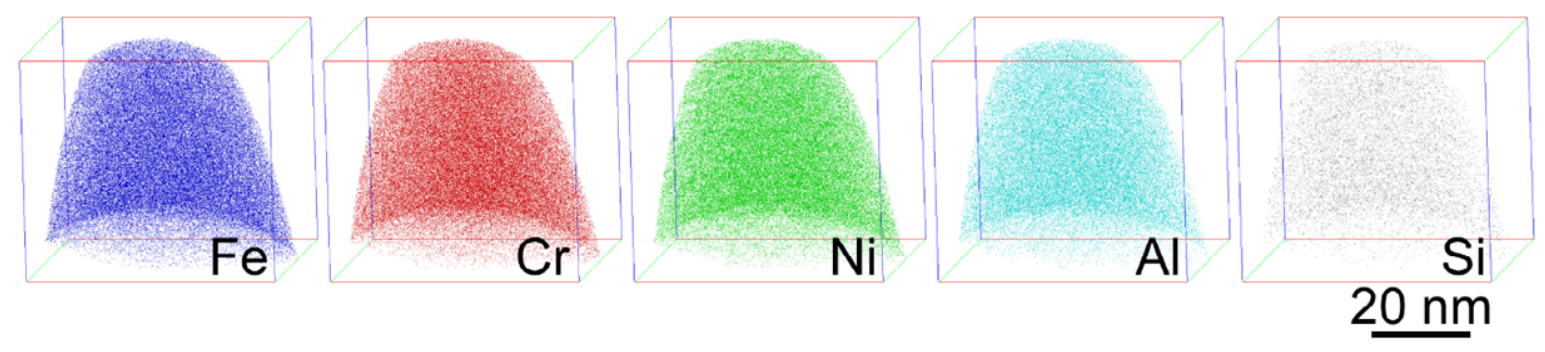

Fig. 6. Atom maps of $\mathrm{Fe}, \mathrm{Cr}, \mathrm{Ni}, \mathrm{Al}$, and $\mathrm{Si}$ of the solution annealed material after 2 dpa proton irradiation. 


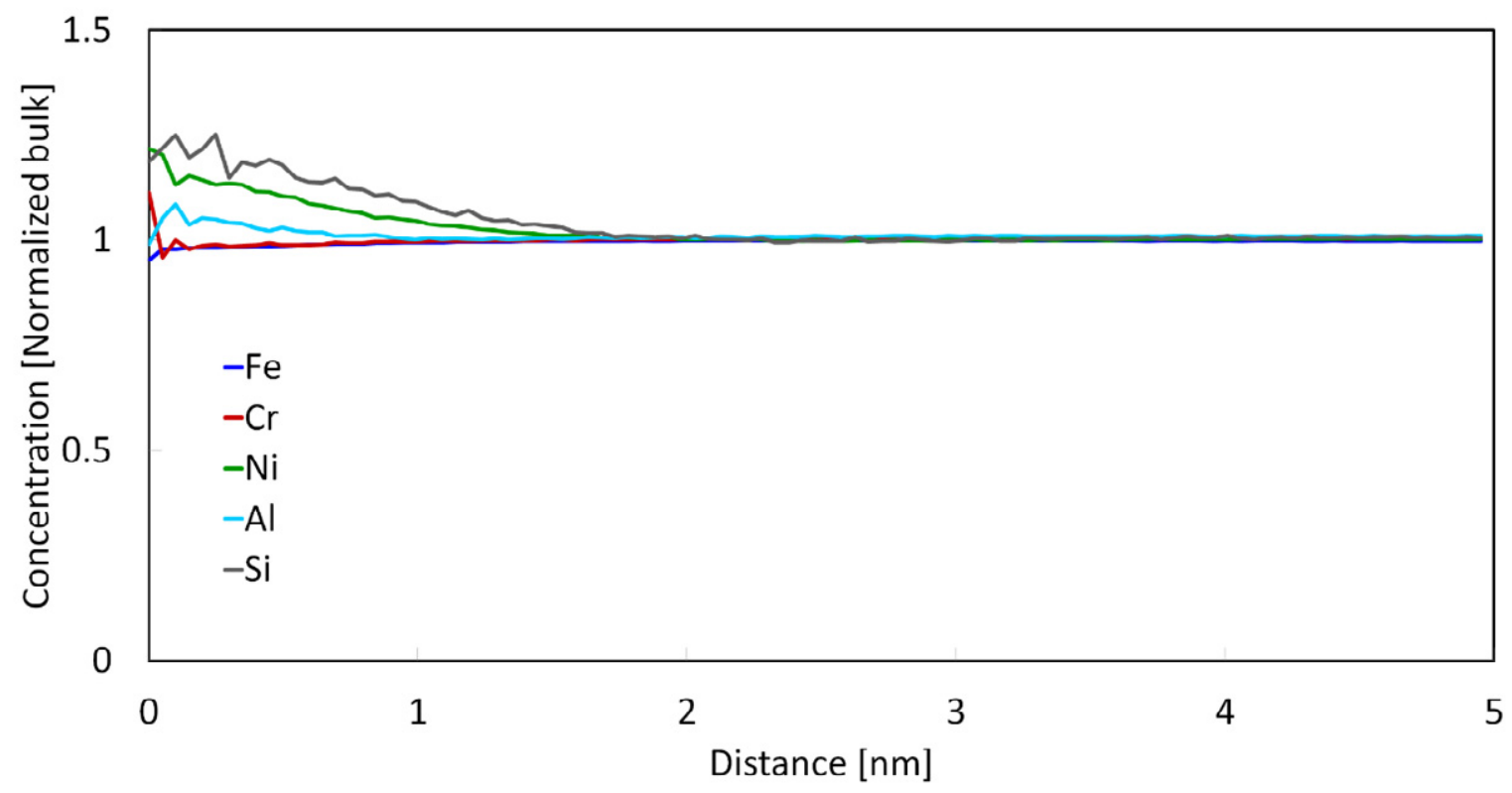

Fig. 7. Radial distribution function of $\mathrm{Ni}$ of the solution annealed condition after proton irradiation.

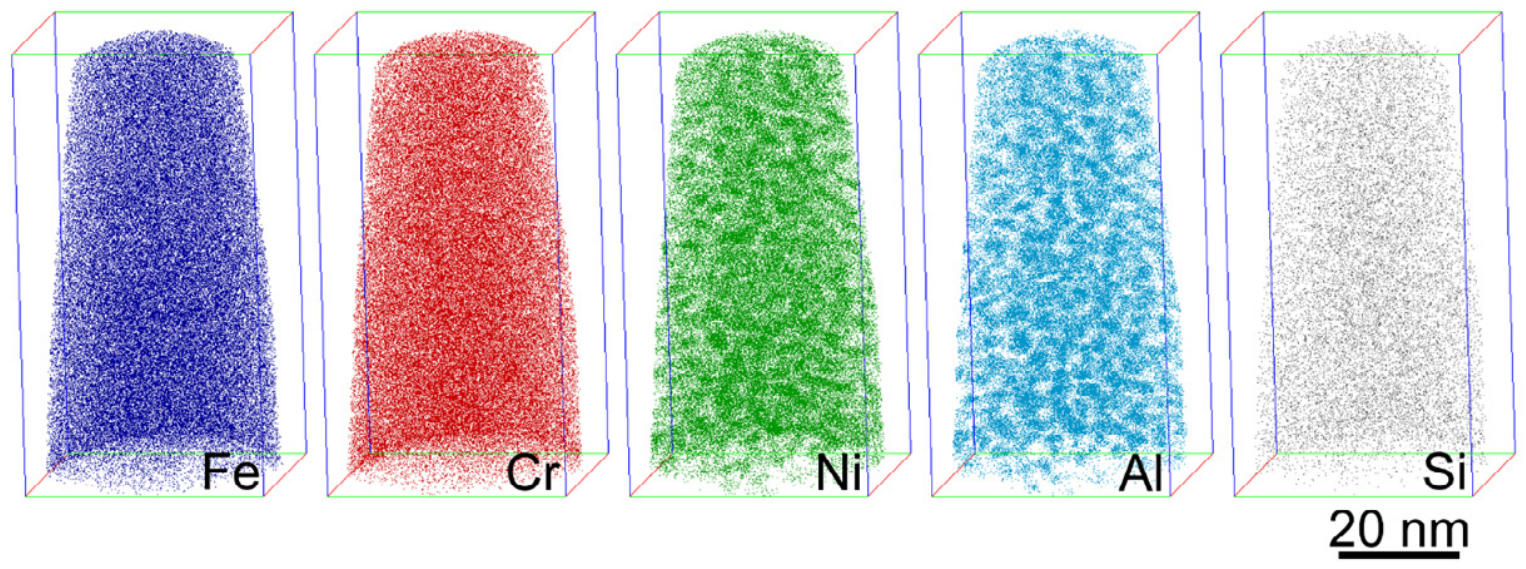

Fig. 8. Atom maps of $\mathrm{Fe}, \mathrm{Cr}, \mathrm{Ni}, \mathrm{Al}$, and $\mathrm{Si}$ of the material after aging for $2 \mathrm{~h}$ at $500^{\circ} \mathrm{C}$. 

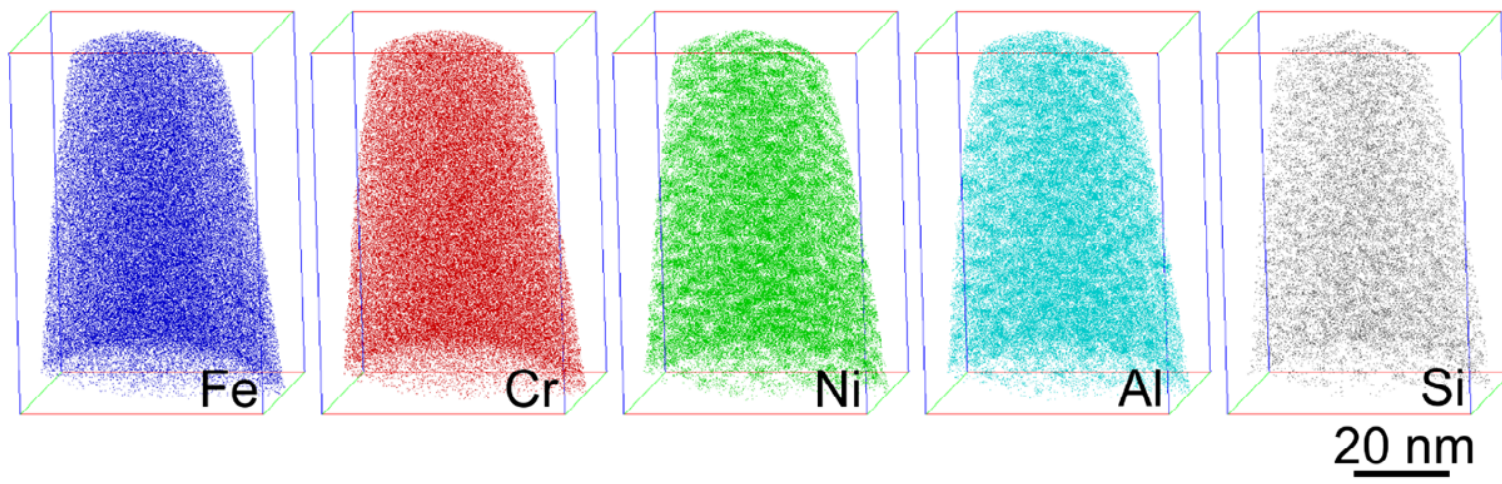

Fig. 9. Atom maps of $\mathrm{Fe}, \mathrm{Cr}, \mathrm{Ni}, \mathrm{Al}$, and $\mathrm{Si}$ after $2 \mathrm{~h}$ of aging at $500^{\circ} \mathrm{C}$ and $2 \mathrm{dpa}$ proton irradiation. 